\title{
Luta pela preservação ambiental: dilemas e contradições
}

\author{
Maria Helena Rauta Ramos \\ Universidade Federal do Rio de Janeiro (UFRJ)
}

\section{Soraya Gama de Ataide}

Escola Superior de Ciências da Santa Casa de Misericórdia de Vitória (Emescam)

\section{Luta pela preservação ambiental: dilemas e contradições}

Resumo: Este artigo procura identificar a relação entre produção capitalista e destruição ambiental. Esta última acentuada na atual conjuntura política, pela orientação econômica de corte neoliberal, dominante hoje no mundo. O resultado desse confronto, apesar de registrar algumas conquistas, expressa-se na agressão aos direitos sociais e ambientais, especialmente nas localidades onde se instalam os grandes empreendimentos de capital privado e multinacional, afetando as condições de vida de comunidades tradicionais ali radicadas. Para elaboração do artigo, utilizou-se de pesquisa bibliográfica, documental e observação direta, tendo como campo a cidade de Anchieta no Espírito Santo, orientadas por uma metodologia de pesquisa participante.

Palavras-chave: Preservação ambiental. Direitos sociais. Lutas sociais. Capitalismo.

\section{Struggle for environmental preservation: dilemmas and contradictions}

Abstract: This article seeks to identify the relationship between capitalist production and environmental destruction, which has become more accentuated in the current political situation under the economic orientation of the neoliberal perspective that is dominant in the world today. The result of this confrontation, despite some conquests, is expressed in the aggression of social and environmental rights, especially in locations where large developments by private and multinational capital affect the living conditions of neighboring traditional communities. The article is based on bibliographic and documental research as well as direct observation in the city of Anchieta in Espirito Santo state Brazil, guided by a methodology of participating research.

Keywords: Environmental preservation. Social rights. Social struggles. Capitalism. 


\section{Introdução}

Encontra-se instalada na cidade de Anchieta, no estado do Espírito Santo, a mineradora Samarco (de capital multinacional), com uma usina e um porto para seu exclusivo uso, desde 1977. Em 2007, colocou em funcionamento a segunda usina, e em 2008, a terceira, que produzem pelotas de ferro para exportação no mercado externo. A principal queixa da população de Anchieta é o "pó preto" depositado nas suas habitações, provenientes das usinas localizadas no interior de seu tecido urbano.

No litoral desta mesma cidade, a Petrobrás mantém um processo de extração de hidrocarbonetos, além da instalação de uma Unidade de Tratamento de Gás (UTG), ligada às plataformas marinhas através de dutos; e, desde 2008, há um projeto para a instalação de uma siderúrgica da empresa Vale, que agravará ainda mais esse quadro local de perigo ambiental.

Em vista desse projeto, a partir de julho de 2008, a Vale, através de institutos de pesquisa, começou um processo de visitação às áreas residenciais que precisam ser removidas para instalação da planta da siderúrgica, desenhada sobre dois bairros: Chapada do A e Monteiro, comunidades tradicionais de descendência indígena. Reuniões abertas ao público (audiências públicas) e reuniões em cada comunidade foram realizadas, para divulgar o projeto e convencer os moradores a desocuparem as áreas.

Os malefícios ambientais, os existentes e os projetados, além de ultrapassarem o ar atmosférico atingem as águas pluviais, os manguezais, o espaço marinho e as lagoas, repercutindo diretamente nas condições de saúde da população local. E como a cidade é ainda pouco desenvolvida, do ponto de vista das relações capitalistas, o movimento de resistência a esse processo é pequeno, envolvendo alguns agentes e poucas organizações na defesa da preservação ambiental.

O objetivo desse artigo é demonstrar os resultados das formas de resistência adotadas por grupos sociais e ambientalistas do município de Anchieta, articulados à rede ${ }^{1}$ de movimentos sociais, existentes no estado do Espírito Santo, e a outros que apoiam a luta contra a insustentabilidade da atual política de desenvolvimento, adotada pelo governo local em consonância com os governos estadual e federal.

Resulta dessa política, para parcelas significativas da população, a agressão aos direitos básicos, a desestruturação das condições de vida e de trabalho e a destruição do meio ambiente, afetando economias tradicionais sustentáveis da região. Estas agressões têm sido toleradas pelos órgãos fiscalizadores do meio ambiente, em sintonia com a política neoliberal, em prol do crescimento da economia e arrecadação do município.

Mas há uma resistência da população local, diretamente afetada, que luta contra a força do interesse do capital e busca reverter o quadro na defesa da manutenção de suas condições de moradia, de saúde e de trabalho, como também da preservação do meio ambiente, encontrando apoio em organizações existentes no Estado, no país e em organismos internacionais.

\section{Metodologia}

O artigo foi baseado em estudos bibliográficos, pesquisa documental e observação direta em campo, orientada por uma metodologia de pesquisa participante. Os dados da empiria, concernentes ao quadro de organizações e lideranças, bem como referentes à contaminação ambiental, começaram a ser coletados a partir do segundo semestre de 2006, fase de elaboração do projeto, quando uma equipe de professores e estudantes (da graduação e posteriormente do mestrado) desenvolveu uma relação junto a grupos sociais existentes nessa cidade, com o objetivo de construir no decorrer do processo uma rede integrada por movimentos sociais na defesa da preservação ambiental.

Este estudo é um dos produtos do projeto integrado de pesquisa Impacto socioambiental e na saúde dos trabalhadores causados pela indústria de Pelotização Samarco e aqueles que serão provocados pela exploração de Hidrocarbonetos no município de Anchieta, do qual participaram, além da Emescam (entidade promotora), a Universidade de Brasília (UnB) e a Universidade Federal do Espírito Santo (UFES), bem como associações de defesa do meio ambiente: Grupo de Apoio ao Meio Ambiente do Município de Anchieta (GAMA); Associação de Pescadores de Ubu e Parati; Colônia de Pescadores do município de Anchieta, entre outras. O Projeto foi apoiado e financiado pelo Fundo de Amparo à Pesquisa do Espírito Santo (Fapes) entre maio de 2008 a maio de 2010, cujo Relatório Técnico Final foi entregue no dia 25 de julho de $2011^{2}$.

A referida pesquisa cumpriu plenamente as exigências da Resolução 196/96 e resoluções posteriores do Ministério da Saúde, recebendo aprovação na reunião da Comissão de Ética em Pesquisa da Escola Superior de Ciências da Santa Casa de Misericórdia, do Espírito Santo, em 27 de junho de 2007 (protocolo n. 089/2007). Aética perpassou todo o processo de trabalho, ressalta-se a questão do sigilo que foi assegurado a todos os sujeitos, bem como o respeito aos autores estudados e a liberdade de resposta e o consentimento dos envolvidos na pesquisa. 


\section{Cenário atual: capital e meio ambiente}

Parte-se do pressuposto, contido na Ideologia alemã, de que: "os indivíduos da época actual são obrigados a abolir a propriedade privada porque as forças produtivas e as formas de troca atingiram um tal nível de desenvolvimento que se tornaram, sob o reino da propriedade privada, forças destrutivas, e porque os antagonismos de classe atingiram o limite extremo" (MARX; ENGELS, s/d, p. 302).

A tendência de falência da propriedade privada observa-se na crise estrutural que atravessa hoje o capitalismo, cujas maiores expressões manifestaram-se a partir do fim de 2008, atingindo as maiores potências do mundo. As iniciativas dos Estados para enfrentar esta crise, no sentido de restabelecer o retorno do crescimento em níveis compatíveis para a acumulação capitalista, contrapondo-se à tendência à queda da taxa de lucro, representam a injeção, no sistema bancário e nas empresas em situação de falência, de grandiosas somas de fundos públicos. Mesmo assim, os resultados quanto a sobrepujar a crise são ínfimos. Primeiro esta explodiu nos Estados Unidos e, posteriormente, repercutiu de forma diferenciada em países da Comunidade Europeia.

O enfrentamento da crise atual, onde o Estado coloca-se claramente como aliado do grande capital, destitui as premissas mais caras do neoliberalismo (que a lógica do mercado é suficiente para garantir o equilíbrio das forças econômicas), o que pode ser o anúncio de uma tendência histórica de superação da propriedade privada e sua substituição por processos de coletivização da produção.

A política econômica, que vem sendo adotada pelo Estado brasileiro e por países da América Latina, desde a primeira metade do século 20, foi explicada pela Teoria da Dependência, ainda na década de 1970, relacionando-a à submissão dos países periféricos ao capitalismo, dependente dos países centrais (MARINI, 1977). Mesmo sujeita a críticas, tenta compreender a reprodução ampliada do sistema capitalista, indicando o aprofundamento da diferenciação, em termos políticos, econômicos e sociais, entre países e regiões, e seu condicionamento dirigido ao desenvolvimento e à expansão de economias dos países centrais.

Essa política também expressa a tendência dominante da divisão internacional do trabalho, resultante da mundialização da economia, sob a égide do neoliberalismo, que desloca os maiores riscos sociais e ambientais para os países periféricos (ou semiperiféricos) ou emergentes. Este processo garante a reprodução de maior valor agregado e de maior poder de controle e direção dos grupos dominantes dos países centrais.

Nesse sentido, há uma transferência para os países periféricos, pelas corporações internacionais, de "partes de suas plantas produtivas - especialmente aquelas demandantes de maior utilização de trabalhadores - deixando nos países industrializados os setores de pesquisa e de desenvolvimento de produtos" (SILVA, 2010, p. 171). Como também a parte poluidora e destrutiva do processo vai de forma mais significativa para os países de economia dependente, menos rigorosos na aplicação de suas leis de proteção ambiental e com abundante força de trabalho - barata, dependente quanto à empregabilidade e política e educacionalmente frágil -, mantendo o seu domínio tecnológico e seus direitos inerentes, inclusive, sob forma de patentes, muitas vezes, ainda auferindo incentivos fiscais e financiamentos.

A atual divisão internacional do trabalho também leva em maior grau, nos países dependentes, à exploração de recursos naturais não renováveis, como o minério e o petróleo, junto com o uso de bens escassos, ali mais abundantes, como a água, a madeira e a extensão de terra. Nesse processo, é mantido o movimento de destruição da natureza e da força de trabalho, a despeito dos efeitos catastróficos dos descartes e poluentes industriais pelos grandes empreendimentos capitalistas, presente em todos os discursos e fóruns sobre a "questão ambiental". mas enfatiza

Em relação a esse processo, Silva (2010, p. 85) ressalta a ação dos movimentos ambientalistas e sociais,

[...] a insuficiência das reformas no campo da 'questão ambiental', posto que a sua produção e reprodução se darão enquanto a sociedade do capital prevalecer, ganhando expressões diversas, de acordo com cada região geopolítica, cada país, cada localidade. As múltiplas facetas que adquire - como partes constitutivas de uma ordem social e ambiental mais ampla - vão revelar, tendencialmente, as contradições centrais do capitalismo na apropriação da natureza.

Entre as diversas linhas do pensamento ambientalista, ressaltamos a fragilidade do conceito de "sustentabilidade" , dominante na agenda da última Conferência de Desenvolvimento Sustentável (Rio+20), paralelamente ao de gestão ambiental. Conceitos estes cujas noções não correspondem ao que se observa em diversas localidades brasileiras e, em particular, na pesquisa realizada em Anchieta, cujo processo produtivo apresenta evidências de "insustentabilidade" com a conivência de órgãos oficiais de fiscalização que, em nome do progresso, apoiam esse processo que destrói a natureza, afeta a força de trabalho e deteriora as condições de vida da população local. 
O conceito de sustentabilidade tem origem no "desenvolvimento sustentável", notabilizado pela Comissão Mundial sobre Meio Ambiente e Desenvolvimento (Cmmad), realizada em 1987, presidida por Gro Harlem Brundtland. A comissão retoma as teses discutidas na Conferência de Estocolmo, em 1972, antecedida pelo Clube de Roma (SILVA, 2010). A ideia central que subjaz a esse conceito, e domina até a Rio+20 (ocorrida em 2012), tem por base o "desenvolvimentismo", buscando ao mesmo tempo enfrentar a tese neomalthusiana, que relaciona o crescimento das populações à pobreza e à degradação do ambiente. Assim, tem sido mantida a contradição, posta desde o Clube de Roma, entre o desenvolvimento econômico e a finitude dos recursos naturais, aceitando o padrão de consumo dos países centrais, mas negando a sua extensão a toda a humanidade.

Desde então, até o documento da Rio+20, não tem avançado as discussões sobre a relação direta entre a produção capitalista e a degradação da natureza e das populações e, consequentemente, a sinalização para sua ultrapassagem. Observa-se justamente o inverso: a defesa do desenvolvimento econômico como requisito para o desenvolvimento social.

Sem alterar o ritmo acelerado de produção destrutiva, são prescritas apenas formas de controlar abusos mais gritantes e, principalmente, meios de combater a pobreza e suas consequências, procurando conciliar o desenvolvimento econômico com o social. Ao explicitar a arena do combate, destacam-se como responsáveis os grupos sociais empobrecidos e não a produção capitalista, que produz a miséria social e a desordem ambiental decrescentemente. Mas como atacar a pobreza se o processo de sua fabricação permanece intacto?

Nesse sentido, a Cúpula dos Povos, realizada no Rio de Janeiro no mesmo período da Rio+20, demonstrou a vitalidade dos movimentos sociais críticos e politizados de todo o mundo (CÚPULA DOS POVOS, 2012). Na representação da Rede Jubileu Sul Américas, com um grupo de 38 redes no Brasil, representadas internacionalmente, este evento apresentou centenas de atividades, plenárias, assembleias e manifestações de rua, que reuniram cerca de 80 mil pessoas (SÁ; JÚNIA, 2012).

O documento síntese, apresentado ao Secretário Geral da Organização das Nações Unidas (ONU), foi focado na convergência anticapitalista, responsabilizando o modelo de desenvolvimento econômico vigente pela crise mundial e pela devastação ambiental e social. Entre as conclusões do evento destacam-se às relativas ao peso dado pela Rio+20 às corporações capitalistas transnacionais representativas do mercado (Coca Cola, Monsanto, Bayer, Siemens, entre outras), como se de fato representassem simbolicamente os países hegemônicos ausentes, apresentando pseudossoluções para os males por elas provocados.

A Cúpula deu ênfase à desautorização dessas corporações de pretenderem representar os interesses da humanidade e de seu futuro, sendo importante registrar que, no final do encontro, um representante dos jovens rasgou o documento da Rio+20 acompanhado por outros segmentos que se retiraram do evento oficial ${ }^{5}$.

\section{Efeitos destrutivos de empresas poluidoras e lutas sociais}

A luta ambiental, travada em Anchieta, tem como foco os efeitos causados por grandes empresas poluidoras (especialmente de mineração e petróleo) ali instaladas, com destaque para a distribuição de material particulado no ar atmosférico, concentrado em maior quantidade no centro do município e nos bairros próximos à indústria de pelotização.

É importante destacar, também, o nível de contaminação das lagoas, especialmente a Lagoa Mãe-Bá, onde são depositados até hoje, pela empresa Samarco, com o aval do Instituto Estadual do Meio Ambiente e Recursos Hídricos (IEMA), os resíduos do processo de pelotização. São relatados por moradores os efeitos causados, ao meio ambiente marinho e ao litoral, local de pesca, pelas dragagens periódicas do porto de propriedade da empresa localizado em Ubu. Acrescentam-se as perfurações e os estudos na mesma localidade, realizados mais recentemente por diferentes empresas, seja sob o comando da Samarco, seja da Petrobrás ou ainda da Vale.

As áreas mais afetadas estão nas comunidades tradicionais de pesca artesanal de Ubu e Parati, onde é desenvolvida uma luta constante, denunciando a redução do espaço de trabalho dos pescadores - ocupado pela instalação do Porto da Samarco (e pelos navios que aí circulam diariamente) -, a redução dos cardumes, provocada pela deterioração do meio ambiente.

Essas mazelas agregam-se aos efeitos das atuais operações empreendidas pela Petrobrás com as construções da Unidade de Tratamento de Gás e a do Gasoduto. Outro processo de destruição é aquele relativo aos manguezais (localizados nas margens do Rio Benevente, onde existe uma área de preservação permanente a Ilha do Papagaio), provocado pela instalação de dois minerodutos, que cortam o rio, para transporte da matéria prima, trazida do município de Mariana (Minas Gerais), deslocando-a até as usinas da empresa Samarco. Está prevista a construção de um terceiro mineroduto, exigido para o funcionamento da quarta usina, aprovado pelos órgãos ambientais, o que certamente aumentará os riscos ao meio ambiente. 
Esse processo de degradação ambiental, com a contaminação das águas, agregada à crescente contaminação do ar, pela difusão cada vez maior de material particulado, vem sendo agravado pela extração de petróleo na costa anchietense, com a exploração, já em processo, de importantes jazidas de hidrocarbonetos, indicado como um dos grandes potenciais para a produção brasileira, inclusive em águas profundas (pré-sal). Além disso, próximo à empresa Samarco, a Petrobras, mantém a torre com um fogo permanentemente aceso, expelindo gases contaminantes no ar atmosférico.

Um fator que cresce em importância, além da destruição do meio ambiente e seu impacto na saúde da população local, é o adensamento populacional, no entorno desses grandes projetos, criando "bolsões de pobreza”, relacionada ao processo de segregação socioespacial, próprio da lógica da produção capitalista ${ }^{6}$. Bairros inteiros foram constituídos a partir da construção das instalações da primeira, segunda e terceira usinas de pelotização. Como se vê, nos dias atuais, com a construção da quarta usina pela Samarco, cresce cada vez mais a ocupação irregular, com levas de trabalhadores que se deslocam para a cidade em busca de melhores condições de vida, com empregos que desaparecerão ao término da obra.

A saúde da população de Anchieta, e especialmente dos pescadores de Ubu e Parati (balneários à beiramar), vem sofrendo danos há várias décadas, com a contaminação ambiental, proveniente do funcionamento das usinas de pelotização, agravada não apenas pela expansão da indústria, mas também na proporção em que a empresa e suas terceirizadas exploram os recursos da natureza sem economia, usando produtos químicos tóxicos, de forma não controlada socialmente. Nas entrevistas ${ }^{7}$, há a indicação de muitos trabalhadores com doenças crônicas alérgicas (gripes recorrentes, bronquite e asma), além daquelas provenientes do esforço enfrentado pela pesca artesanal, o que pode ser constatado também em óbitos, conforme levantamento realizado no cartório de registro de documentos.

Há um elevado índice de morte por câncer e doenças no aparelho respiratório, que incidem especialmente sobre os mais velhos, pois há mais tempo encontram-se expostos à poluição ambiental, iniciada na década de 1970. Para responder às necessidades desse processo industrial destrutivo do meio ambiente, uma logística será implantada, em termos de meios de comunicação, transportes e de equipamentos e serviços coletivos, exigidos pelo adensamento populacional, provocado pela migração de trabalhadores (do próprio estado e de outros), composta na maioria de mão de obra sem qualificação, solicitada pelas empreiteiras nessa primeira fase de implantação de projetos, e de outros vindos, inclusive do exterior, para atender à demanda de mão de obra especializada.

Desse modo, há o crescimento das necessidades sociais nas áreas de habitação, saúde, educação, cultura e lazer (parques e jardins). A ação estatal, conjugada à iniciativa privada, pode responsabilizar-se, em curto e médio prazo, pela antecipação do remodelamento e da ampliação dessa condição geral de produção. Mas esse processo de reestruturação urbana também produz ônus para a população local, não apenas pelos transtornos provocados em seu quotidiano, mas pela destruição ambiental que também provoca. Por exemplo, no balneário de Iriri, localizado na zona urbana de Anchieta, a maior parte das árvores, centenárias, ali existentes, foi cortada sob o pretexto de alargamento das avenidas e instalação de rede de esgoto. Pôde-se observar o último verão (2012-2013) a elevação da temperatura, em relação a anos anteriores.

Quaisquer forças sociais que surjam no município, levantando esses dados, são consideradas inimigas do "progresso", e mal vistas tanto pelas empresas como por órgãos governamentais, quando a missão destes últimos poderia ser, ao contrário, fazer cumprir a lei para a preservação do meio ambiente. As audiências públicas constituem-se em meros cumprimentos de requisitos legais, e não espaços públicos de debate, de controle social e/ou de contestação. As questões mais importantes não são respondidas, seja removendo-as para outros contextos e outras ocasiões, ou diluídas com respostas evasivas.

Quanto a contestações a esse quadro, que algumas vezes exigia o confronto direto com as empresas responsáveis, até 2005, havia apenas a Colônia de Pescadores de Anchieta e uma liderança comunitária local, insuficientes para o encaminhamento das lutas referentes à redução do espaço da pesca e dos cardumes e à deterioração do meio ambiente. Uma instituição de luta foi organizada, em 2006, unindo as duas comunidades - Ubu e Parati - em torno desse objetivo: a Associação de Pescadores, atualmente com estrutura legitimada e legalizada e com uma diretoria combativa, que luta pela defesa das condições de vida e de trabalho dos associados, em sua maioria, pescadores artesanais. Em suas reuniões discutem as dificuldades e os problemas enfrentados, principalmente com as atividades das grandes empresas (Samarco, Petrobras e Vale) e os organismos dos governos federal, estadual e municipal (com destaque para IEMA e o Instituto Brasileiro do Meio Ambiente e dos Recursos Naturais Renováveis - Ibama). Nesse espaço são definidas as estratégias de ação e as táticas requeridas a cada situação, dando preferência aos encaminhamentos que levam à negociação, somente em último caso são definidos procedimentos de ação direta.

As lutas desenvolvidas para a preservação ambiental têm encontrado grandes barreiras, principalmente dentro do próprio quadro de algumas organizações ambientais, dados os vínculos institucionais estabelecidos 
dos grupos dominantes com a empresa mineradora. Uma exceção é o GAMA, com tradição na região. A luta contra a instalação da siderúrgica da Vale tem sido enfrentada por pequenos segmentos sociais de Anchieta, e com o apoio de representantes da sociedade civil do estado do Espírito Santo. O grupo GAMA divulgou seu desacordo em relação à instalação de uma siderúrgica no município:

[...] somos contrários a esta instalação, com base nos seguintes argumentos: [...]. Já observamos uma recorrente ocupação irregular em alguns bairros de municípios da região [...]. Também se registra um aumento no quadro da violência urbana, do tráfico de drogas e de prostituição, inclusive infantil. Esta última se agravará exponencialmente com a divulgação dos empregos (provisórios) que serão criados se a Siderúrgica for aprovada. [...]. Comunidades tradicionais do município de Anchieta serão afetadas, ou pior desaparecidas, caso o projeto da Siderúrgica da Vale venha ser implantado. Estamos nos referindo especialmente à comunidade da Chapada do A, cujos habitantes são os últimos descendentes da aldeia indígena encontrada pelos jesuítas (em torno de 9.000 indivíduos) [...]. O impacto que o complexo industrial instalado em Anchieta (Samarco e Petrobrás) tem sobre nossas áreas de preservação ambiental - Estação Ecológica Papagaios e APA da Guanabara (além do Monte Urubu) visivelmente afetadas com a instalação dos minerodutos e gasodutos, além dos terminais marítimos -, será elevado grandemente caso a Siderúrgica da Vale venha se instalar nessa região (que traz juntamente um Mega Porto e a Variante Ferroviária Litorânea Sul [...] (RAUTARAMOS, 2011, p. 1).

Soma-se a esse contexto, as iniciativas de privatizar espaços de acesso ao mar, não apenas pelas indústrias, mas também por particulares em áreas da marinha valorizadas que foram cercadas e vêm sendo colocadas à venda, dado o crescimento da renda fundiária urbana provocada por estes investimentos e o anúncio de novos empreendimentos. Alguns moradores tentam denunciar esse processo, e adotar formas de enfrentamento a pretensos proprietários, que se sentem no direito de fechar espaços de domínio da marinha para seu exclusivo uso.

Nesse processo de luta, foi criada a Rede Comuna Verde integrada pelo GAMA, pelas Associações de Catadores de Caranguejo de Anchieta, de Pescadores de Ubu e Parati, e por diversos militantes que apoiam a luta dos moradores de Chapada do A, que, organizada em Associação de Moradores, teima em não vender seus terrenos. O Partido Verde é sem expressão na localidade, uma vez que diversos integrantes mantém vínculos com a empresa Samarco, como seus empregados diretos ou de empreiteiras, ou então pertencentes ao quadro municipal. Os políticos locais (vereadores e prefeito) ou defendem expressamente os interesses das empresas poluidoras ou agem com cautela quanto a se manifestar contra tais empreendimentos.

O elevado grau de deterioração do meio ambiente em Anchieta tende a aumentar, não apenas em contaminação do ar atmosférico como também das águas marinhas (local de descarte do material colhido pelas dragagens do Porto da mineradora e de exploração pela Petrobrás), dos manguezais e das lagoas, com destaque para a Lagoa Mãe-Bá (frágil leito de água que sofre ainda hoje com o depósito dos resíduos das usinas da Samarco).

\section{Conquistas do movimento social e da luta ambiental}

Uma das principais lutas da Associação de Pescadores de Ubu e Parati foi àquela relacionada ao conflito criado, em 2006, pelos impactos da Plataforma Itapuã nas primeiras operações de sondagem geotécnica para estudo da viabilidade de construção de mais um porto em Ubu, o terminal marítimo da Petrobrás. Esta estatal, como também o próprio IEMA e outras entidades responsáveis pelas operações, não consideraram os danos que suas atividades provocariam na pesca artesanal.

Os pescadores, na Praia do Além (em Ubu), foram surpreendidos pela invasão da plataforma em sua área de pesca. Diversos contatos foram mantidos, especialmente com os órgãos municipais que não se posicionaram a favor dos pescadores. A contenda foi finalmente resolvida em fevereiro de 2008, com o pagamento de uma indenização pelos danos causados aos pescadores e pelas dificuldades financeiras durante quatro meses sem pesca (de outubro de 2006 a fevereiro de 2007), solução dada após várias reuniões de conciliação.

Algumas outras disputas encontram-se em curso. São lutas relacionadas a diversos interesses da população local, como, por exemplo: preservação dos pontos pesqueiros; funcionamento do Telecentro em Parati; construção de um Centro de Convivência em Ubu, pela Petrobrás; ressarcimento dos prejuízos causados pela Vale com as perfurações no litoral da pesca, para sondagem geotécnica de construção de um grande porto; pelos danos provocados pela Samarco na última dragagem de seu porto, realizada no ano 2011, quando a pesca foi impedida aos pescadores artesanais; projeto de instalação de uma indústria de confecção destinada às mulheres dessas duas localidades; o término de construção do campo de futebol da comunidade; e a luta pela concessão de renda básica de cidadania aos pescadores artesanais de Anchieta, atingidos pelas empresas poluidoras do meio ambiente. 
No que diz respeito às dragagens periódicas realizadas para funcionamento do Porto da Samarco, o resultado é a destruição da vida marinha, dado o deslocamento de grandes quantidades de areias formando bancos em locais onde anteriormente existiam os viveiros de peixes; além de furos subterrâneos provocados pelo uso de dinamites. São situações que contaminam as águas do mar e reduzem o espaço da pesca artesanal.

Quanto ao depósito dos resíduos no fundo do mar, que acabam destruindo a vida marinha, há a solução proposta pela Associação de Pescadores de Ubu e Parati, que sejam bombeados para a terra sob os dispositivos definidos pelos órgãos ambientais (IEMA e Ibama), para garantir a manutenção dos corais e a preservação de cardumes, o que é essencial para o trabalho dos pescadores artesanais e para a manutenção da vida no planeta Terra.

Os pescadores de Inhaúma (comunidade de pescadores mais distante do centro de Anchieta) denunciaram o desmatamento realizado pelo capital imobiliário em áreas do condomínio da Aldeia de Iriri, situação que se repetiu no condomínio Moréia Tênis \& Beach. O IEMA, diante das denúncias, impediu a continuidade do desmatamento e, através de ato formal, decretou o reflorestamento das áreas atingidas. Soma-se a essas conquistas o afastamento definitivo do projeto da siderúrgica da Baosteel, empresa chinesa, que pretendia em 2006 instalar-se na cidade de Anchieta, em área limite com a zona rural. O próprio governo estadual, finalmente, baseado em parecer técnico da Secretaria de Meio Ambiente, afirmou na imprensa que a água da bacia do rio Benevente era insuficiente para atender a esse grande empreendimento, além de que o ar já estava suficientemente saturado de material particulado, originário da mineradora, nos limites permitidos por lei.

Mas as organizações locais de defesa do meio ambiente e os grupos ambientalistas ainda tinham que enfrentar novos desafios. Surge um novo projeto, a instalação da Companhia Siderúrgica de Ubu (CSU), capitaneado exclusivamente pela Vale. Esta empresa, que se diz nacional, mas que tem seu capital constituído, em grande parte, por acionistas estrangeiros, passou a desenvolver diferentes estratégias de desmobilização, promovendo cursos de liderança e adquirindo terras por preços elevados.

Lutar contra esse cenário exigia aglutinação de forças, inclusive estaduais, nacionais e internacionais, pois a CSU, tanto quanto a Vale, é considerada uma empresa brasileira, e congrega para seu projeto o apoio dos governos local, estadual e federal, do Ministério Público local e dos órgãos de controle ambiental (IEMA e Ibama).

A trajetória dessa luta e de suas pequenas conquistas foi descrita em "Nota", apresentada por representante de Chapada do A - quando a Vale fez noticiar sua desistência do projeto CSU, no jornal Valor (em 31 de janeiro de 2013) - ao Comitê Político da Articulação Internacional dos Atingidos pela Vale, reunido no Rio de Janeiro, nessa mesma data. Segundo a nota em questão, os embates começaram a ocorrer, principalmente após as reuniões promovidas pela Vale com a comunidade tupiniquim de Chapada do A, e alguns ambientalistas locais.

Para instalação da CSU, a Vale necessitava erradicar os moradores da comunidade de Chapada do A, local onde residiam desde seus ancestrais: "Foi aí que tudo começou, em termos de juntar as poucas forças contra esse mega empreendimento. [...]. Formou-se nesse momento na Assembleia uma massa unívoca contra a Vale, saindo da prática o slogan "Fora a Vale de Anchieta" (RAUTA RAMOS, 2013, p. 1).

O movimento ganhou força na imprensa da Grande Vitória ${ }^{8}$ através de uma série de notícias ressaltando o anseio da comunidade em não "se deixar erradicar da localidade de Chapada do A". A materialidade dessa luta ficou expressa na constituição do movimento de Defesa Permanente de Anchieta, formado pela OAB, Famopes, partidos de esquerda, Movimento dos Sem Terra (MST), Central Única dos Trabalhadores (CUT) e outras entidades sindicais, que passaram a estar presente na comunidade de Chapada do A, congregando-se às já existentes forças de oposição.

Representantes desse movimento fizeram um plebiscito em Chapada do A, que foi divulgado na imprensa, no qual 97\% dos moradores responderam não pretender, de forma alguma, vender sua propriedade para essa empresa, aglutinando-se em torno do slogan "Fora a Vale de Anchieta". Depois disso, funcionários da Vale, e de empresas por ela contratada, fizeram visitas à Chapada do A de forma recorrente, pressionando os chefes de famílias, geralmente pessoas idosas, a vender suas propriedades.

Mas a comunidade estava preparada para resistir: "Numa dessas visitas, a equipe da Vale estava acompanhada de funcionários da prefeitura local, para fazer medições nos terrenos de cada família, quando foram tocados para fora da comunidade, pelas mulheres, instrumentalizadas de cabo de vassoura nas mãos. Isso tudo foi divulgado na imprensa" (RAUTA RAMOS, 2013, p. 1).

Com o apoio de organizações ambientalistas do estado do Espírito Santo, especialmente da Rede Alerta Verde, da Via Campesina e do MST, houve, na sequência, outra conquista, coberta pela imprensa: a ocupação do IEMA, durante a sessão para concessão da licença provisória. Com essa ocupação, pelos militantes ambientalistas, o IEMA ficou paralisado um dia, tendo como resultado:

[...] uma entrevista com a Presidente do IEMA (que aconselhou a comunidade de Chapada do A a recorrer à Funai para comprovar sua ascendência indígena) e a cópia imediata do EIA-Rima da CSU (que até aquele 
momento tinha sido negada) e a inclusão na decisão do IEMA, de conceder licença provisória, de mais uma condicionante: a Vale deveria refazer o layout da planta da CSU para permitir a permanência de Chapada do A, nesse mesmo território (RAUTA RAMOS, 2013, p. 2).

Em 2012, a Vale foi obrigada pelo Conselho de Cultura do estado do Espírito Santo a retirar o nome de Chapada do A, da placa instalada no alto do morro, em frente ao conjunto habitacional em construção, destinado às famílias que seriam removidas do local de instalação da CSU. Mas uma "grande vitória", segundo os moradores da localidade, foi a não recondução da atual gestão do município de Anchieta, nas eleições em 2012, que era favorável ao projeto CSU.

A vitória eleitoral do candidato da oposição teve apoio dos grupos sociais que integram o movimento "Fora a Vale de Anchieta", na medida em que esse se comprometeu a lutar a favor das reivindicações das organizações cuja bandeira é: "Basta a poluição da Samarco em Anchieta. Queremos retornar à vocação tradicional do município, lutando a favor de um turismo ecológico, da agricultura orgânica e da preservação da pesca artesanal" (RAUTA RAMOS, 2013, p. 2). Dessa forma, a Vale ficou definitivamente sem sustentação política para manter seu projeto em Anchieta.

A crise mundial do capital, pano de fundo de todas as ações realizadas pelo movimento "Fora a Vale de Anchieta", revelou, provocando a retração da indústria: a redução da demanda de aço e a queda de seu preço no mercado. Isso obrigou a Vale a reduzir suas pretensões e abandonar definitivamente o empreendimento da indústria siderúrgica. "Assim, não restava à Vale outro caminho senão enterrar de vez seu projeto de instalação em Anchieta/ES da CSU, empresa siderúrgica altamente poluente e destruidora dos recursos

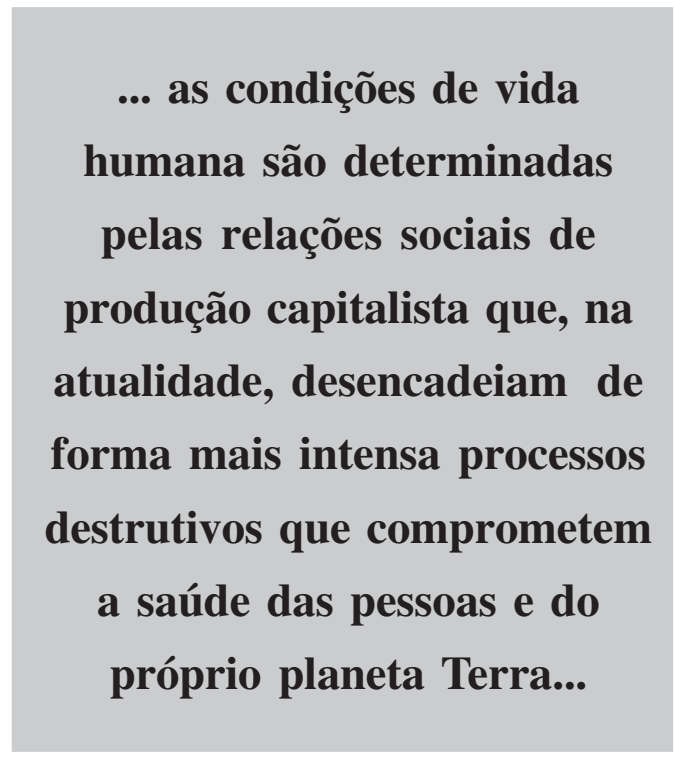
naturais" (RAUTA RAMOS, 2013, p. 2).

Esse resultado não ocorreu exclusivamente por determinações da crise econômica, mas decorreu da resistência de moradores de Anchieta, em especial, a comunidade tupiniquim de Chapada do A, apoiados por organizações que defendem a preservação do meio ambiente: a Via Campesina, o MST, a Rede Alerta Verde e a Articulação Internacional dos Atingidos pela Vale.

\section{Considerações finais}

Considera-se importante o caso aqui relatado, de forma sumária, não apenas para ilustrar a resistência de comunidades tradicionais, mas também, por invalidar muitos dos discursos e das correntes de defesa do meio ambiente que advogam a conciliação entre a economia capitalista e a preservação ambiental.

Os dados da pesquisa demonstram uma dupla realidade: a primeira, relatada nos documentos oficiais, consensual e sistêmica; e a segunda, a dura realidade enfrentada por moradores, ocultada nos discursos, mas revelada através da análise dos múltiplos riscos e efeitos da poluição junto à população local.

A pesquisa permite as seguintes generalizações: a) as condições de vida humana são determinadas pelas relações sociais de produção capitalista que, na atualidade, desencadeiam de forma mais intensa processos destrutivos que comprometem a saúde das pessoas e do próprio planeta Terra; b) as contradições sociais, manifestadas no espaço local, estão relacionadas à exploração do trabalho pelo capital, e à grande desigualdade entre os países, entre as classes e frações de classes, que geram relações de dominação/ dependência sob os ângulos econômico, social, cultural e político; c) o crescimento do pensamento crítico e da ação em direção à superação do metabolismo social destrutivo, envolvendo empresas capitalistas e meio ambiente, a exemplo da aglutinação de forças sociais no movimento encaminhado pela Articulação Internacional dos Atingidos pela Vale, como também aquele verificado na Cúpula dos Povos em 2012, na cidade do Rio de Janeiro.

Esses movimentos sociais, articulados internacionalmente, em expansão continuada, poderão impulsionar a pressão social para o redirecionamento da política econômica dos governos, no sentido de desatar as amarras de dependência que os prendem às grandes empresas monopolistas e, progressivamente, caminhar na ultrapassagem do modo de produção capitalista. 


\section{Referências}

ATAIDE, S. G. de. Capital, trabalho, saúde e meio ambiente: uma relação destrutiva analisada em uma indústria de pelotização. 2011. 226 f. Tese (Doutorado em Serviço Social) - Programa de Pós-Graduação em Serviço Social, Universidade Estadual do Rio de Janeiro, Rio de janeiro, 2011.

CÚPULA DOS POVOS. Declaração final da cúpula dos povos na Rio+20. Disponível em: <http://cupuladospovos.org.br/2012/06/ declaracao-final-da-cupula-dos-povos-na-rio20-2/>. Acesso em: 30 jul. 2012.

FOLADORI, G. O metabolismo com a natureza. Crítica marxista, São Paulo, n. 12, p. 105-117, jan./jun. 2001. Disponível em: <http:/ /www.unicamp.br/cemarx/criticamarxista/>. Acesso em: 20 dez. 2010.

FOSTER, J. B. A ecologia de Marx: materialismo e natureza. Tradução de Maria Teresa Machado. Rio de Janeiro: Civilização Brasileira, 2005.

MARX, K.; ENGELS, F. A Ideologia Alemã. Tradução de Conceição Jardim e Eduardo Lúcio Nogueira. Lisboa: Presença; São Paulo: Martins Fontes, [s.d].

MÉSZÁROS, I. A crise estrutural do capital. Tradução de Francisco Raul Conejo et al. São Paulo: Boitempo, 2009.

RAUTA RAMOS, M. H.; ATAIDE, S. G.; SILVA, A. I. Metamorfoses sociais e políticas urbanas. Rio de Janeiro: DP\&A, 2002.

RAUTA RAMOS, M. H. Desenvolvimento local, saúde e meio ambiente. Espírito Santo: Emescam, 2009.

. Macaé hoje, Anchieta amanhã: a ação destrutiva do capital. Anchieta: Edição do autor, 2011.

. Nota da articulação internacional dos atingidos pela Vale em relação com a CSU em Anchieta-ES. Rio de Janeiro: Edição do autor, 2013.

RAUTA RAMOS, M. H; BORGES, L. H. Projeto integrado: impacto socioambiental e na saúde dos trabalhadores causados pela indústria de pelotização Samarco e aqueles que serão provocados pela exploração de hidrocarbonetos no município de Anchieta-ES. Fapes: Vitória, 2011. Relatório final.

MARINI, R. M. Dialéctica de la dependência. Cidade do México: Era, 1977.

SÁ, E.; JÚNIA, R. A Cúpula dos Povos foi anticapitalista. Entrevista com Sandra Quintela. Caros Amigos, São Paulo, n. 184, p. 34-36, jul. 2012.

SILVA, M. G. Questão ambiental e desenvolvimento sustentável: um desafio ético-político ao Serviço Social. São Paulo: Cortez, 2010.

UNIC-Centro de Informação das Nações Unidas. Rio+20: o futuro que queremos. Disponível em: <http:// www.ofuturoquenosqueremos.org.br/about.php>. Acesso em: 30 jul. 2012.

\section{Notas}

1 Rede Alerta Verde, Via Campesina, Movimento dos Sem Terra, e núcleos de partido de esquerda e respectivas centrais sindicais, Ordem dos Advogados do Brasil (OAB); Federação das Associações e Movimentos Populares do Espírito Santo (Famopes).

2 Ver Rauta Ramos e Borges (2011).

3 Em uma perspectiva crítica, a concepção de sustentabilidade encontra-se em: Foster (2005); Foladori (2001) e Rauta Ramos (2009).

4 "Rio+20" também conhecida como Conferência das Nações Unidas Sobre o Desenvolvimento Sustentável, ocorrida pela primeira vez em junho de 2012 - EcoRio 92. Na Conferência Rio+20 líderes mundiais, juntamente com diversas vertentes políticas, entidades públicas, privadas e ONGs, tentaram formular soluções que tinham o intuito de reduzir a pobreza, promover maior igualdade social e assegurar a segurança ambiental no planeta que sofre com o crescimento populacional. As discussões oficiais ficaram em torno de dois temas principais: o desenvolvimento da economia verde de forma sustentável e a retirada das pessoas da pobreza; e, também, como ampliar a coordenação internacional para o desenvolvimento sustentável (UNIC, 2012).

5 Nessa lógica, o Documento Oficial da Rio+20 (UNIC, 2012) reitera essas “teses", apresentando 58 cláusulas de combate à pobreza e seus derivados. No total, apenas 50 compromissos, sem metas, são firmados, existindo 124 cláusulas de reconhecimento de compromissos anteriores não realizados, com retrocessos e maior deterioração, sendo ainda reafirmados princípios desde a Declaração dos Direitos Humanos, em 55 cláusulas. Em seu discurso de encerramento da Rio+20, a Presidenta Dilma Roussef celebra a construção do consenso em torno do documento, cuja afirmação expressa as dificuldades diante das lentas forças mundiais: "celebrar conquistas consensuais significa reconhecer que construções coletivas, baseadas na difícil arte do diálogo, são mais fortes, porque são de todos. São essas conquistas que fazem o mundo avançar”'. Disponível em: <http://www2.planalto.gov.br/ imprensa/discursos/discurso-da-presidenta-da-republica-dilma-rousseff>. Acesso em: 15 ago. 2012.

6 Ver a concepção de segregação socioespacial em Rauta Ramos, Ataide e Silva (2002).

7 Ver Ataide (2011).

8 Região metropolitana de Grande Vitória é formada pelos municípios de Cariacica, Fundão, Guarapari, Serra, Viana, Vila Velhae Vitória. 
Maria Helena Rauta Ramos

rauta.ramos@gmail.com

Doutora em Serviço Social pela Pontifícia Universidade Católica de São Paulo (PUC/SP)

Professora aposentada da Escola de Serviço Social da Universidade Federal do Rio de Janeiro (UFRJ)

\section{Soraya Gama de Ataide}

sorayagama@hotmail.com

Doutora em Serviço Social pela Universidade do Estado do Rio de Janeiro (UERJ)

Professora adjunta do Departamento de Serviço Social na Escola Superior de Ciências da Santa Casa de Misericórdia (Emescam/ES)

\section{Emescam - Departamento de Serviço Social}

Av. Nossa Senhora da Penha, n. 2190

Santa Luzia

Vitória - Espírito Santo - Brasil

CEP: 29045-402 